
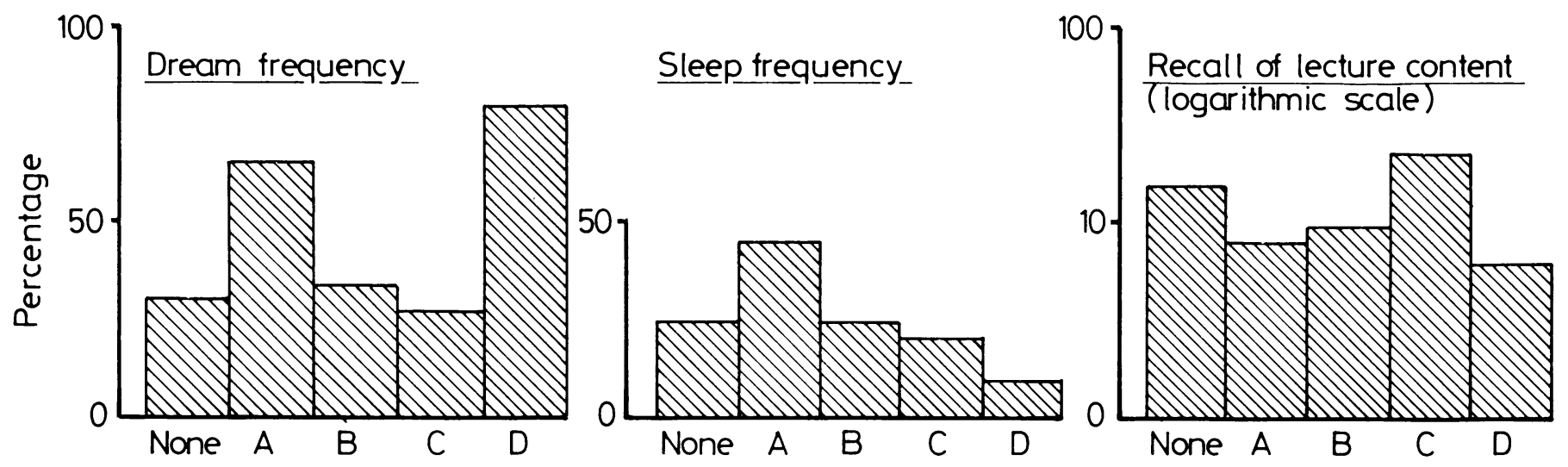

FIG 3-Effects of the different grades of extraneous material on dream and sleep frequency and recall of lecture content.

\section{Summary and conclusions}

During a series of presentations of scientific papers $40.6 \%$ of 276 subjects reported dreaming, but only $18 \cdot 1 \%$ actually fell asleep. The frequency of dreaming was significantly increased by the addition of either "very boring" or "very interesting" slides to the usual ones, but not by "neutral" slides. The recall of lecture content and the proportion of audience asleep were (surprisingly) not greatly affected by the addition of extraneous slides of any sort. On the other hand, adding "very interesting" slides greatly increases audience enjoyment.

I am very grateful to all those who helped in the preparation of this paper and of the poster on which it was based, particularly Simon Tutty and Peter Cox of the Department of Medical Illustration,
Frenchay Hospital. I thank Jennifer Harvey, Judy Seward, and Julia Flenley, who carried out the typing in secret, and Dr Alex Paton and Dr Stephen Lock for their helpful suggestions. Some of the illustrations and "extraneous material" came from Dr Janet Albano, $\mathrm{Mr}$ Roger Celestin, Dr Glaciomar Machado, Dr Francis Page, Dr Paul Serviour, and Dr Roger White. The pictures in fig 2 are reproduced by courtesy of the American Physiological Society, the New England fournal of Medicine, the Financial Times, the Sunday Times, Express Newspapers, Athena International, Steven Spielberg and Universal International Pictures, and the American Gastroenterological Association, and I am most grateful to them all.

We are also particularly indebted to the 12 lecturers who took part in the study. It has, unfortunately, not been possible to include them as coauthors. They have been unable to give their permission for this in time, owing to absence on speaking engagements abroad.

\title{
The critical attitude in medicine: the need for a new ethics
}

\author{
NEIL MCINTYRE, KARL POPPER
}

\begin{abstract}
"These standards of objective truth and criticism may teach him (the individual man) to try again and to think again; to challenge his own conclusions, and to use his imagination in trying to find whether and where his own conclusions are at fault. They may teach him to apply the method of trial and error in every field, and especially in science; and thus they may teach him how to learn from his mistakes, and how to search for them. These standards may help him to discover how little he knows and how much there is he does not know. They may help him to grow in knowledge, and also to realise that he is growing. They may help him to become aware of the fact that he owes his growth to other people's criticism and that reasonableness is readiness to listen to criticism."
\end{abstract}

KARL POPPER, 1978

Mistakes occur in medicine as in other walks of life. Their consequences may be trivial, but often they are serious, and they may be catastrophic. Some errors cannot be helped; others are avoidable, even culpable. Steps may be taken to correct errors but in

Royal Free Hospital School of Medicine, London NW3 2QG

NEIL MCINTYRE, MD, FRCP, professor of medicine

Penn, Buckinghamshire

SIR KARL POPPER, CH, PHD, FRS, philosopher many instances the mistake is irrevocable; the only benefit is the prevention of similar errors in future. Doctors are expected to profit from their experiences, and from their earliest days medical students are exhorted to learn from their mistakes. To learn only from one's own mistakes would be a slow and painful process and unnecessarily costly to one's patients. Experiences need to be pooled so that doctors may also learn from the errors of others. This requires a willingness to admit that one has erred and to discuss the factors that may have been responsible. It calls for a critical attitude to one's own work and to that of others.

Unfortunately medical students and doctors see little evidence of such openness around them. Gorowitz and MacIntyre wrote: "No species of fallibility is more important or less understood than fallibility in medical practice. The physician's propensity for damaging error is widely denied, perhaps because it is so intensely feared. ... Physicians and surgeons often flinch from even identifying error in clinical practice, let alone recording it, presumably because they themselves hold ... that error arises either from their or their colleagues' ignorance or ineptitude."1 But errors need to be recorded and to be analysed if we are to discover why they occurred and how they could have been prevented.

If errors are not to be repeated it is important that certain attitudes, deeply rooted in the profession, are overcome. 
Professional attitudes are often determined by professional ethics, by the principles that determine whether ideas or actions are considered right or wrong. These also influence professional etiquette, the rules of behaviour towards colleagues and, more important, towards patients.

Learned professions are based on knowledge and skill. Not surprisingly the ethics of a profession are strongly influenced by its members' view of the nature of knowledge and of the methods by which it is acquired, both collectively and personally. These factors dominated the prolonged debates and arguments preceding the Medical Acts of the nineteenth century, which led to formal professional recognition for registered practitioners. ${ }^{2}$ Professional ethics still reflect the ideas of that time.

The scientific revolutions of the twentieth century have, however, important implications for all professions. They challenge long established ideas about the growth of knowledge and about the nature of science. They call into question the basis of professional ethics. We think that traditional professional ethics, based on old views of the growth of knowledge, tend to hinder progress and performance. We submit suggestions for a new professional ethics, hoping that they will be discussed and that the discussion will influence professional attitudes and behaviour.

\section{Growth of knowledge: accumulation or correction?}

The old view of the growth of knowledge, especially of scientific knowledge, is still widely held. According to this view, knowledge grows by accumulation: we discover and collect more and more facts. This view is not, of course, totally mistaken. Knowledge does grow, here and there, by accumulation. Yet far more often knowledge grows by the recognition of error-by the overthrow of old knowledge and mistaken theories. Even the discovery of a new species can be the correction of a previous hypothesis. What was regarded as one virus may prove to be several different viruses (or vice versa).

The erroneous hypothesis may have stated a non-existent causal relationship: catarrhal obstruction of the bile ducts was thought to cause epidemic jaundice (now thought to be due to viral hepatitis); a mistaken observation may lead to an anatomical myth such as that of a direct connection between the right and left ventricles of the heart. Or a fundamental but mistaken theory may be proposed, such as Darwin's theory of pangenesis. We think that revisions of such hypotheses, which may have the character of major or minor revolutions, are more important and more characteristic than the finding of new facts.

Obviously, any person regarded as a scientific authority may make a mistake, even a fundamental one. Flaws may exist in an accepted scientific doctrine-even in one regarded as particularly well established and secure. Thus almost all chemical measurements had to be revised after Urey's discovery of heavy water in 1931.

The great men of science are original researchers who make discoveries that revolutionise their subject. But even they make mistakes. Einstein, perhaps the most original thinker of our time, repeatedly mentioned some of his mistakes. He pointed out that it took him more than 12 years to discard Mach's positivism. According to his friend Max Born, he adhered, from about 1920 to his death in 1955, to a research programme (the search for an unified field theory) that became outdated in 1936 with Yukawa's theory of nuclear forces.

There is no absolute certainty in science. Scientific knowledge is conjectural, hypothetical. As a consequence there can be no authorities.

What we might call the "old" professional ethics are based on the search for objective truth and on the ideals of rationality and intellectual responsibility. But the old ethics are built on the view that scientific knowledge can be certain knowledge, that knowledge grows normally by accumulation, and that it can be acquired and stored in a person's mind. These ideas create an environment favourable to the emergence of authorities. To be an authority became an ideal of the old professionalism.

These ideas have terrible consequences. Authority tends to become important in its own right. An authority is not expected to err; if he does, his errors tend to be covered up to uphold the idea of authority. Thus the old ethics lead to intellectual dishonesty. They lead us to hide our mistakes, and the consequences of this tendency may be worse even than those of the mistake that is being hidden. They influence our educational system, which encourages the accumulation of knowledge and its regurgitation in exminations. Students are punished for mis- takes. Thus they hide their ignorance instead of revealing it; this makes it difficult for them, and for their teachers, to correct their deficiencies.

It is this situation which leads us to propose a "new" professional ethics. Our proposals are arguable and may be summed up in 10 theses.

(1) Our present conjectural knowledge far transcends what any person can know, even in his own specialty. It changes quickly and radically and in the main not by accumulation but by the correction of erroneous doctrines and ideas. Therefore there can be no authorities. There can, of course, be better and worse scientists. More often than not, the better the scientist the more aware he will be of his limitations.

(2) We are all fallible, and it is impossible for anybody to avoid all mistakes, even avoidable ones. The old idea that we must avoid them has to be revised. It is mistaken and has led to hypocrisy.

(3) Nevertheless, it remains our task to avoid errors. But to do so we must recognise the difficulty. It is a task in which nobody succeeds fully-not even the great creative scientist who is led, but quite often misled, by intuition.

(4) Errors may lurk even in our best tested theories. It is the responsibility of the professional to search for these errors. In this he can be helped greatly by the proposal of new alternative theories. Thus we should be tolerant of ideas that differ from the dominant theories of the day and not wait until those theories are in trouble. The discovery that a well tested and corroborated theory, or a commonly used procedure, is erroneous may be a most important discovery.

(5) For all these reasons our attitude towards mistakes must change. It is here that ethical reform must begin. For the old attitude leads to the hiding of our mistakes and to forgetting them as fast as we can.

(6) Our new principle must be to learn from our mistakes so that we avoid them in future; this should take precedence even over the acquisition of new information. Hiding mistakes must be regarded as a deadly sin. Some errors are inevitably exposed-for example, operating on the wrong patient, or removing a healthy limb. Although the injury may be irreversible the exposure of such errors can lead to the adoption of practices designed to prevent them. Other errors, some of which may be equally regrettable, are not so easily exposed. Obviously, those who commit them may not wish to have them brought to light, but equally obviously they should not be concealed since, after discussion and analysis, change in practice may prevent their repetition.

(7) It is therefore our task to search for our mistakes and to investigate them fully. We must train ourselves to be self critical.

(8) We must recognise that self criticism is best but that criticism by others is necessary and especially valuable if they approach problems from a different background. We must therefore learn to accept gracefully, and even gratefully, criticism from those who draw our attention to our errors.

(9) If it is we who draw the attention of others to their mistakes we should remind ourselves of similar errors we have made. We should remember that it is human to err and that even the greatest scientists make mistakes.

(10) Rational criticism should be directed to definite, clearly identified mistakes. It should contain reasons and should be expressed in a form which allows its refutation. It should make clear which assumptions are being challenged and why. It should never contain insinuations, mere assertions, or just negative evaluations. It should be inspired by the aim of getting nearer to the truth; and for this reason it should be impersonal.

We submit these ten theses for discussion and improvement, hoping to show through them that even in the field of ethics it is possible to make proposals which can be rationally discussed and improved.

\section{Implications of our new professional ethics for medicine}

Patients expect to benefit from medical care. They consult a doctor because of his skill. They trust him to exercise his knowledge and skills to the best of his ability, and they assume that he will take all reasonable steps to ensure a favourable outcome.

To what extent are patients' expectations justified ? Errors by doctors are common. ${ }^{4}$ Some errors are innocent and unavoidable, others culpable. Whatever the character of the mistake it is obviously the responsibility of doctors to try to reduce the likelihood of error. But whereas doctors may acknowledge this responsibility in principle there is little evidence that they spend much time analysing their errors, 
either in clinical practice or even during their training. To do so adequate case records are needed, notes which allow the causes and consequences of errors to be identified. But as Gorowitz and MacIntyre wrote: "It is not common clinical practice to keep full and systematic records of medical and surgical error. But without detailed records of erroneous diagnoses and prognoses, of unpredicted side effects, of failures of effect of treatment, and the like, we cannot provide the empirical basis necessary for any adequate theory of the limitations of the predictive powers of physicians."

It is true that few clinical records allow assessment of the relation between medical care and its outcome. Records are often illegible, their order may be jumbled, and there are often inaccuracies and omissions. Not only do they hinder the analysis of errors but they may actually cause error, as information vital for patient management is often lost in the chaos. From the poor quality of doctors' notes one might infer lack of interest in the recording and evaluation of care. Records need to be improved if they are to be used for analysing individual cases. Without good records audit is virtually impossible.

\section{Evolution of medical audit}

Formal collection of hospital records and statistics was advocated by Percival in his Medical Ethics, ${ }^{3}$ by Florence Nightingale in her Notes on Hospitals, ${ }^{5}$ and by Groves in an article in the BMF in $1908 .^{6}$ They all argued that it would help the systematic improvement of hospital treatment. Their pleas fell on deaf ears.

In 1910 Flexner published a scathing attack on the standard of American medical schools and hospitals. ${ }^{7}$ It led to drastic changes in American medical schools and stimulated the Clinical Congress of North America to announce plans for the reform of hospital care and of surgical practice. The Congress was influenced by Codman, who had resigned from the Massachusetts General Hospital because of his dissatisfaction with the standards of surgical care. ${ }^{8}$ Codman set up his own hospital; he published abstracts of all cases admitted to it between 1912 and 1916 and analysed unfavourable results. He advocated critical appraisal of the care of individual cases, arguing that it would help to unearth correctable deficiencies and to improve the overall quality of medical care.

Codman's views were in advance of his time. ${ }^{9}$ His zeal alarmed some doctors, and no hospital fully accepted his challenge to analyse and compare cases according to his proposals. The American College of Surgeons took over the work of Codman and his colleagues and introduced a "hospital standardisation programme." But this was limited to five aspects: medical staff organisation: qualifications for medical staff membership; rules and policies governing professional work in the hospital; medical records; and diagnostic and therapeutic facilities. Its results were beneficial. Yet this programme omitted the analysis of outcome and the identification of avoidable errors, the two points with which Codman was most concerned.

There were sporadic but unsuccessful attempts to promote audit of patient care during the '20s and '30s. After the second world war interest revived; surgical studies provided the impetus. ${ }^{41011}$ They showed wide variation in the performance of different hospitals, and of individual surgeons in the same hospitals, but, more importantly, it was found that when surgeons were told of the findings the number of "unjustified" operations fell dramatically. Subsequent studies of medical problems, such as diabetes and pneumonia, showed similar variations in the performance of physicians. ${ }^{11}$ Since then many similar studies have been reported ${ }^{412}$ and in most instances there was evidence indicating corrigible deficiencies in medical care.

Only a few of these studies tried to assess whether performance improved as a result of the study. So it has been questioned whether audit has any practical consequences. It has been argued that effort to identify deficiencies would be wasted if they could not be corrected. When such an assessment was made, however, there was usually evidence that performance did improve. ${ }^{1011}{ }^{13-23}$ Almost all of these studies emphasised the importance of critical evaluation, of the feeding back of information. The value of "feedback" in the modification of behaviour cannot be doubted. It is a fundamental biological process: it is the basis of all learning, of "profiting from experience," of "learning from mistakes."

\section{Attitudes to audit and peer review}

Unfortunately, but understandably, many doctors are antagonistic to audit. They resent the idea that their work should be reviewed. As Sir Douglas Black stated: "There are strong public and parliamentary pressures to bring medical practice under closer scrutiny, whether by the Ombudsman, or in some other way. Some members of the profession maintain that such pressures are to be resisted, without argument and without compromise, and that we should have nothing to do with medical audit, quality control, or whatever." ${ }^{24}$

There are many reasons why doctors, individually and as a profession, resist the idea of audit and peer review. Workers in almost every subject resent the suggestion that the quality of their work should be checked. Supervision is usually accepted, and often welcomed, by those in training; but consultants and principals in general practice have clearly finished their formal training. It is taken for granted that they are capable not only of working without supervision but also of supervising the work of junior hospital staff or trainees. Established practitioners have always enjoyed complete professional autonomy. To suggest that their work should be checked seems to imply that their work is not entirely satisfactory and that their performance needs improvement. If the problem is viewed in this light it is not surprising that they should resent the idea. But the purpose of peer review is to improve performance even if the work is already of a high standard. The best golfers and pianists seek the opinion of others in order to maintain their standards, and the best scientists are grateful for the criticism of their colleagues. One may suspect that willingness to accept criticism increases with the quality of the worker, and with his self reliance.

The reluctance of people to have their work evaluated is closely linked with their reluctance to comment on, or to complain about, the behaviour of others. Most people "live and let live." This attitude, we admit, is not only understandable: it is invaluable. Social life depends on it. Who should throw the first stone? Who indeed can really distinguish between an honest mistake and culpable negligence? This is why we believe that efforts to improve performance must come from a desire for self improvement, a desire based on an essentially ethical insight. Audit must not be part of a disciplinary instrument; it must be a tool for learning by feedback.

Far from expecting criticism from colleagues when things go wrong, doctors usually turn to them for reassurance and support. As Friedson has pointed out, the usual reaction to untoward consequences is to feel free of reproach ${ }^{25}$; having done one's best one cannot be responsible for untoward results. Even when error is conceded it tends to be excused in some way. "It is often verbalised in order to get reassurance from friendly colleagues. By conceding error to friends who will not themselves criticise, one gains the cathartic benefits of confession while avoiding the price of penance." Self criticism is thus acceptable; criticism by others is not and those who offer it may be viewed as troublesome meddlers.

\section{Centrality of the doctor-patient relationship}

Two other factors peculiar to medicine, and both of great importance, affect doctors' attitudes to peer review. The first lies in the character of their work; the second is the nature of the doctor-patient relationship.

When a patient asks for help the doctor wants to respond. He may take action for its own sake, perhaps for its placebo effect, on the assumption that doing something is better than doing nothing. Each doctor assumes personal responsibility for the way in which he manages his patients and does so on the basis of his own clinical experience. Yet, unavoidably, much of this is anecdotal, a mythology based on his own individual cases, and on hearsay. Doctors rarely observe the work of their colleagues at first hand; they rely on their own approach and on their own ability, so their work tends to be self validating and self confirming. ${ }^{25}$ It is difficult to view it critically because a doctor must believe in what he is doing in order to go on practising. These factors encourage personal rather than collective responsibility. They exaggerate the acceptability of opinions that vary from person to person, and sustain a well intentioned resistance to revision of one's own way of practising, even if others were to disapprove. They encourage what may be termed "relativism" in clinical practice (see below).

As for the second factor, many doctors believe that audit and peer review would threaten the doctor-patient relationship. This relationship is founded on the acknowledged skill of the doctor, but also on his patients' fears. His authority may crumble should patients hear of mistakes.

Criticism by patients is relatively uncommon. Not only are they rarely aware of the relevant facts, but they tend to trust their doctor. They want to keep his goodwill and may fear that a dispute would sour any subsequent dealings with him, and with other doctors. They may not know how to get a better doctor. Doctors also fear disputes, 
particularly those which might result in litigation, and it is hardly surprising that a doctor should try to conceal his error, or that doctors should close ranks around a colleague when mistakes occur.

One might expect doctors to be less concerned about criticism within a small professional group. But this is also viewed with disfavour. Some doctors argue correctly that patients' faith in their doctor is of therapeutic importance and believe that it would be damaged if patients realised that errors were relatively common. To patients regular peer review might imply that the skill of doctors was limited and did not justify the great faith placed in them. The public might adopt a more "realistic" attitude towards doctors and whereas this might be desirable from many points of view it would reduce the therapeutic value of the doctor-patient relationship. Furthermore, the fact that defects in the care of individual patients might be exposed, albeit in private, must cause concern to doctors that this information could be made available should a dispute subsequently arise.

All these arguments merit consideration. Peer review should be resisted if it threatened the doctor-patient relationship without offering substantial benefits. Yet we believe that patients would welcome efforts to improve clinical performance; they would have good grounds for resentment if they knew that doctors were resisting the opportunity to improve their work. Patients, after all, do know that mistakes occur; and the doctor-patient relationship should surely depend on mutual trust rather than on mystique. It might even improve if patients knew that doctors cooperated in an attitude of mutual criticism.

It seems intuitively obvious that medicine should be open and accountable, and there is ample evidence ${ }^{26}$ of the "public and parliamentary pressures to bring medical practice under closer scrutiny" spoken of by Sir Douglas Black. ${ }^{24}$ We believe for many reasons that both the medical profession and the public would be better served if this scrutiny was initiated by doctors and not by outside pressures. The process requires the full cooperation of the profession and would fail if it could be viewed in an adversial context. It is an explicit responsibility of a profession to keep its house in proper order, and only its members have the relevant knowledge to do so. The issues are usually delicate and open discussion would be resisted in the presence of lay observers. Review must be carried out regularly in the context of day to day practice; this rules out systems which require cumbersome administration. Various types of audit may prove useful; experiments and experience are needed to decide which methods will be best in particular situations.

\section{Relativism versus an open mind}

In clinical practice many issues are clouded, and there are often times when there is no clear solution to a medical problem. This reinforces a relativistic approach-the view is that truth is relative, that there are no objective standards, that standards vary from individual to individual or from group to group. As mentioned above, relativism is also encouraged by the professional independence of the doctor. He believes in his own approach and places emphasis on personal rather than collective responsibility. But for many problems a better course of action may already have been established, either from the cumulative experience of colleagues, or as a result of carefully controlled clinical trials. When this is so, there is little defence for relativism.

To answer and reject relativism in medicine (and in other areas) is a matter of importance. We are all fallible and we therefore should doubt that which appears to us to be true, and should question even those moral and ethical principles which we hold dear. But in questioning them we should be searching for something better. Truth may be hard to come by, but we must recognise that if we acknowledge our errors we may, with effort, get nearer to the truth, and we may be able to prevent such errors in future. Like all knowledge and all skills, those of the doctor improve if errors are identified and if this information is fed back. Hence we must never cease our critical search for truth. We must keep an open mind and must always try to learn from those who hold a different view. Precisely for this reason we must reject relativism. It is good to say "You may be right and I may be wrong"; if both parties say it this will be evidence of mutual toleration. But to avoid relativism we must say more than this. We must add: "But we may both be wrong. By talking things over rationally we may be able to correct some of our mistakes; perhaps both of us will get nearer the truth, or act in a better way."

\section{A licence to license}

We have offered several explanations for the antagonism of many doctors to criticism and to having their work reviewed. We believe that they are bound up with the old professional ethics which we discussed earlier, and with the old ideal of the authority who knows his own subject and does not make mistakes. The pertinence of these arguments for medicine seems clear. All doctors derive "authority" from their skill and knowledge. This is acknowledged by the act of qualification and by subsequent registration. Also there is a hierarchy of "authority" within the profession, based on the further acquisition of knowledge and special skills. Authority does resist challenge, and, clearly, if the performance of individual doctors was found not to live up to expectation then they would suffer a sense of shame and a loss of self esteem. This is an important reason why mistakes are covered up and why only a few doctors seem to welcome the possibility that they might be uncovered.

The medical profession was granted an effective monopoly over the right to practise on the assumption that it would be responsible for the standards of its members. "Professional accountability therefore cannot be restricted to the question of one's own personal competence; it includes also the question of the competence of the guild. The right to pass judgment on colleagues carries with it the duty so to judge; otherwise doctors profit from a monopoly established by the state without enforcing those standards the need for which alone justified the monopoly. The licence to practise is based on the prior licence to license. If the licence to practise carries with it the duty to practise well, the licence to license carries with it the duty to judge and monitor well." 25 This responsibility has been neglected. Friedson, ${ }^{26}$ May, ${ }^{25}$ and Kennedy ${ }^{26}$ are highly critical of the failure of doctors to regulate and improve professional standards, and the cynical lay person might be forgiven for viewing the tolerance of doctors towards their fellows as a manifestation of collective professional self interest.

Medical education today places too little emphasis on the ethical aspects of medicine, either at the undergraduate or the postgraduate level. Many doctors equate the term "medical ethics" with medical etiquette. This preoccupation with interprofessional relations worries many lay observers. Recent public debates on brain death, euthanasia, and the management of malformed infants have shown clearly a widespread dissatisfaction with the way in which doctors are trained to accept moral responsibilities. Some ethical problems may be the concern of specialists but the problem of improving patient care is the concern of all doctors. The ethical problems involved in medical practice in general deserve at least as much attention as the somewhat specialised problems of abortion or euthanasia.

\section{A new ethos}

In monitoring medical care tolerance is essential and in the search for mistakes there should be no denigration of others nor any condemnation associated with the process of peer review. It would be morally wrong and would deter doctors from taking part. The goal must be educational and practical: it must be linked to the improvement of all doctors and not to the punishment of those who err. Only with such an ethos can we establish a new type of confidence: that mutual criticism is not personal and perjorative but that it springs from a mutual respect and a desire to improve the lot of patients.

If this view is accepted certain consequences follow naturally. It then becomes important not only to acknowledge mistakes but to search for them, in order to correct them as quickly as possible. Not only would we learn from our errors but others would learn from them as well. When errors are due to lack of skill we will, we hope, try to improve our skill; and when, as is sometimes the case in medicine, our errors are due to carelessness, or our failure to do what we know we ought to do, then we will look for ways of improving our behaviour.

Our ideas are not as revolutionary as they seem. A tradition similar to the one the medical profession should emulate still exists among great artists and scientists and among musiciains. Around 1513 Durer wrote: "But I shall let the little I have learnt go forth into the day in order that someone better than I may guess the truth, and in his work may prove and rebuke my error. At this I shall rejoice that I was yet a means whereby this truth has come to light." 28 This spirit is still alive, and needs encouragement, not only in artists and scientists, but in doctors and those in other walks of life.

We are grateful to the friends and colleagues who have read and criticised several drafts of this paper. 


\section{References}

${ }^{1}$ Gorowitz, S, MacIntyre A. Toward a theory of medical fallibility. $\mathcal{F}$ Med Philos 1976;1:51-71.

${ }^{2}$ Newman C. The evolution of medical education in the nineteenth century. London: Oxford University Press, 1957.

${ }^{3}$ Percival T. Medical ethics. 3rd ed. Oxford: John Henry Parker, 1849.

+Williamson JW. Improving medical practice and health care. Cambridge, Mass: Ballinger, 1977

${ }^{5}$ Nightingale F. Notes on hospitals. 3rd ed. London: Longman, 1863.

${ }^{6}$ Groves EW. Surgical statistics : a plea for uniform registration of operation results. Br Med F 1908; ii :1008-9.

7 Flexner A. Medical education in United States and Canada. New York: Carnegie Foundation, 1910.

* Codman EA. A study in hospital efficiency: the first five years. Boston: Thomas Todd Co, 1916. (Available from University Microfilms, Ann Arbor, Michigan.)

${ }^{9}$ Lembcke PA. Evolution of the medical audit. $7 A M A$ 1967;199:534-50.

10 Lembcke PA. Medical auditing by scientific methods: female pelvic surgery. F $A M A$ 1956;162:646-55.

$"$ Eisele CW, Slee VN, Hoffman RG. Can the practice of internal medicine be evaluated? Ann Intern Med 1956;44:144-61.

12 Brook RH, Williams $\mathrm{KN}$, Avery AD. Quality assurance today and tomorrow: forecast for the future. Ann Intern Med 1976;85:809-17.

${ }^{13}$ Achong MR, Theal HK, Wood J, Goldberg R, Thompson DA. Changes in hospital antibiotic therapy after a quality of use study. Lancet 1979; ii: $1118-22$.

14 Dyck FJ, Murphy FA, Murphy JK, et al. Effect of surveillance on the number of hysterectomies in the province of Saskatchewan. $N$ Engl $\mathcal{F}$ Med 1977;296:1326-8.

15 Godber G. The confidential enquiry into maternal deaths. A limited study of clinical results. In: McLachlan G, ed. A question of quality? Roads to assurance in medical care. London: Oxford University Press, 1976:23-33.
16 McColl I. Observations on the quality of surgical care. In: McLachlan G, ed. A question of quality? Roads to assurance in medical care. London: Oxford University Press, 1976:49-61.

17 de Dombal FT. Computers and the surgeon-a matter of decision. Surg Annu 1979;11:33-7.

18 Brook RH, Williams KN. Effect of medical care review on the use of injections. Ann Intern Med 1966;85:509-15.

19 Lohr KN, Brook RH. Quality of care in episodes of respiratory illness among medicaid patients in New Mexico. Ann Intern Med 1980;92: 99-106.

${ }^{20}$ Huntley RR, Steinhauser R, White KL, Williams TF, Martin DA, Pasternack BS. The quality of medical care: techniques and investigations in the out-patient clinic. F Chronic Dis 1961;14:630-42.

${ }^{21}$ Kincaid WH. Quality assurance in health care: are the PSROs working in the US. (Prepapers for 8th International Congress on Health Records. Ed Velthoven JJ.) The Hague, Netherlands: Congress Centre, 1980 183-9.

22 Aylett $M$. Bookings at a general practitioner obstetric unit; an exercise in peer review. $\mathrm{Br} M$ ed $\mathcal{F} 1977$;ii :28-9.

${ }^{23}$ Verby JE, Holden P, Davies RH. Peer review of consultations in primary care: the use of individual recordings. $\mathrm{Br}$ Med 7 1979; 1 :1686-8.

24 Black D. Apples of discord. 7 R Soc Med 1981;74:92-100.

${ }^{25}$ May WF. Code and covenant or philanthropthy and contract? In: Reiser SJ, Dyck AJ, Curran WJ, eds. Ethics in medicine: historical perspectives and contemporary concerns. Cambridge Mass: MIT Press, 1977:65-76.

${ }^{26}$ Friedson E. Profession of medicine: a study of the sociology of applied knowledge. New York: Dodd, Mead \& Co, 1975.

23 Kennedy I. Consumerism in the doctor-patient relationship. (The Reith Lectures.) The Listener 1980 Dec $11: 777-80$.

${ }^{28}$ Durer A. Durer's Schriftlicher Nachlass. Lange K, Fuhse F, eds. Haller as der Salle: Max Niemeyer, 1893.

(Accepted 24 March 1983)

\section{SHORT REPORTS}

\section{Small bowel perforation due to a Christmas cake decoration}

Perforation of the bowel by an ingested foreign body is surprisingly uncommon given the probable frequency with which various sharp indigestible objects are swallowed. We report a case which illustrates that even the most innocuous looking object is not without danger.

\section{Case report}

An 86 year old woman who lived alone presented as an emergency with a two day history of persistent abdominal pain, initially over the lower abdomen but later generalised. She had vomited several times and had not passed flatus or faeces for 24 hours. She was febrile and in pain with a pulse rate of 90 per minute and a blood pressure of $160 / 190 \mathrm{~mm} \mathrm{Hg}$. Abdominal examination showed signs of generalised peritonitis. At laparotomy a small amount of free fluid was found, with a fibrinous exudate on the small bowel. A pointed object was seen protruding through the ileum, $25 \mathrm{~cm}$ proximal to the ileocaecal valve. On removal this was found to be a small plastic robin, whose beak had perforated the bowel wall (figure). A local resection of the damaged bowel was performed and the patient made an uneventful postoperative recovery. On questioning later, she remembered eating a piece of Christmas cake two or three days before admission.

\section{Comment}

Henderson and Gaston quoted an incidence of perforation of $1 \%$ in a series of 800 patients who had swallowed foreign bodies. ${ }^{1}$ More recently Gunn reported four new cases of intestinal perforation by swallowed sharp foreign bodies in south east London over 10 years, ${ }^{2}$ and Ward-McQuaid reported six cases from the Oxford area over a similar length of time. ${ }^{3}$ The largest published series is that of McManus, who reviewed 95 published case reports up to $1938 .{ }^{4}$ Half of these patients were under 30 and he found that the incidence decreased with each successive decade. Other studies have shown a more scattered distribution in 32 cases. ${ }^{2} 35$ Snodgrass emphasised the association of swallowing foreign bodies with the loss of touch sensation that occurs with the use of dentures. ${ }^{5}$

Most patients present with a history of acute onset of pain and vomiting, and local or generalised peritonitis, but 24 of the 74 patients

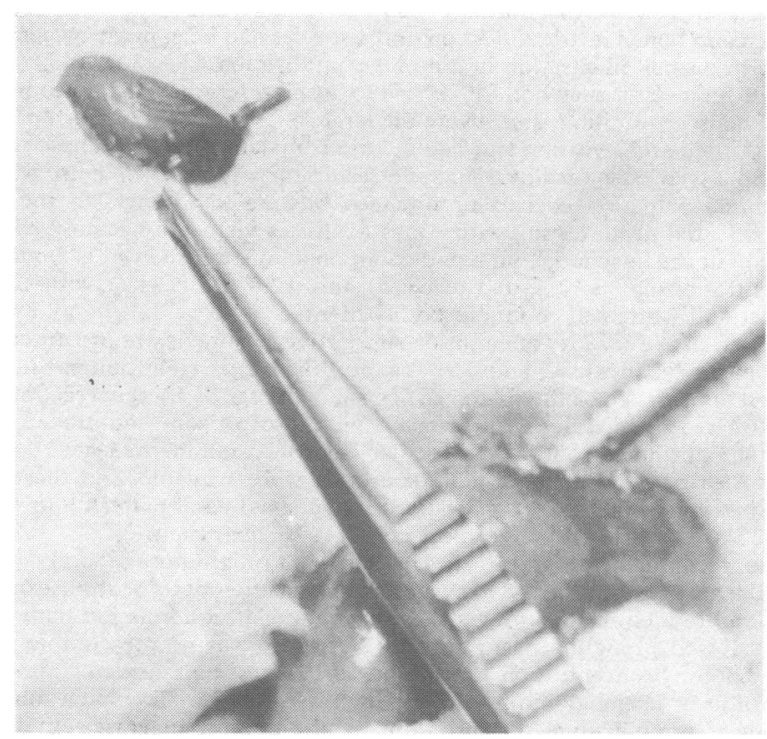

Christmas robin being removed from small bowel.

whose details were available to McManus had a history of longer than two weeks, presenting with fever, localised pain, or a mass. Perforation has been seen in all parts of the small and large bowel but most perforations occur in the region of the ileocaecal valve, particularly including the appendix and, to a lesser extent, Meckel's diverticulum and simulate acute appendicitis in their presentation. The most common perforating agents are sharp metallic objects, especially pins or wire, meat or fish bones, and tooth picks or wood splinters. This case highlights the danger, particularly to those wearing dentures, of decorating food with small sharp objects.

We thank Mr W G T Bell for permission to report this case.

${ }^{1}$ Henderson FF, Gastron EA. Ingested foreign body in the gastrointestinal tract. Arch Surg 1938;36:66-95. 